\title{
Disseminated carcinomatosis of the bone marrow from pancreatic cancer: a case report
}

\author{
Hiroki Namikawa', Yasuhiko Takemoto ${ }^{1 *}$ (D), Ayako Makuuchi', Masanori Kobayashi', Shigeki Kinuhata', \\ Mina Morimura', Takashi Ikebe ${ }^{1,2}$, Hiromu Tanaka ${ }^{3}$ and Taichi Shuto ${ }^{1}$
}

\begin{abstract}
Background: Most cases of disseminated carcinomatosis of the bone marrow (DCBM) arise from gastric cancer. DCBM from pancreatic cancer is very rare. We herein present a case of DCBM from pancreatic cancer.

Case presentation: A 57-year-old man was referred to our hospital for severe lumbago. Laboratory data indicated that he suffered from disseminated intravascular coagulation (DIC). Non-contrast abdominal computed tomography (CT) revealed multiple bone masses but no other abnormal findings. Left iliac bone marrow biopsy revealed poorly differentiated adenocarcinoma cells. Positron emission tomography (PET)-CT showed diffuse abnormal uptake in the bones and tail of the pancreas. Contrast whole-body CT showed a tumor measuring approximately $28 \mathrm{~mm}$ in diameter with poor enhancement in the tail of the pancreas. The patient's final diagnosis was pancreatic cancer located in the tail of the pancreas with diffuse bone metastases and DIC. His DCBM was thus believed to originate from the pancreatic cancer. He succumbed to the disease approximately 2 months after admission to our hospital.
\end{abstract}

Conclusion: We herein describe a case of pancreatic cancer located in the tail of the pancreas with diffuse bone metastases and DIC, which, in our case, was DCBM. Therefore, in cases of DCBM with an unknown primary tumor, pancreatic cancer should be considered during differential diagnosis.

Keywords: Disseminated carcinomatosis of the bone marrow, Disseminated intravascular coagulation, Diffuse bone metastases, Pancreatic cancer

\section{Background}

Disseminated carcinomatosis of the bone marrow (DCBM) caused by solid tumors is often accompanied by disseminated intravascular coagulation (DIC) [1]. The prognosis of patients with DCBM is generally very poor [2]. Approximately $80-90 \%$ of all DCBM cases are found in stomach cancer patients. [3]. However, DCBM arising from pancreatic cancer is extremely rare. We herein report the case of a 57 -year-old man who had pancreatic cancer located in the tail of the pancreas with diffuse bone metastases and DIC.

\footnotetext{
* Correspondence: yatakemoto@med.osaka-cu.ac.jp

${ }^{1}$ Department of Medical Education and General Practice, Osaka City

University, Graduate School of Medicine, 1-4-3, Asahi-machi, Abeno-ku, Osaka

545-8585, Japan

Full list of author information is available at the end of the article
}

\section{Case presentation \\ Case description}

A 57-year-old man was referred to our hospital for severe lumbago. His symptoms appeared approximately 3 months prior to referral. After experiencing such symptoms for about a month, the patient consulted an orthopedist. A lumbar spinal radiography showed no significant findings. Despite treatment for pain relief, his lumbago persisted. At presentation, the patient reported no particular past medical history or known allergies. His medication included oxycodone hydrochloride hydrate, loxoprofen sodium hydrate, rebamipide, prochlorperazine maleate, and magnesium oxide. He did not smoke or consume alcohol, and worked as a designer. His mother had diabetes mellitus, hypertension, and hepatocellular carcinoma, and his sister had colon cancer. On physical examination, the patient weight $82 \mathrm{~kg}$ and was $174 \mathrm{~cm}$ tall. His blood pressure was 
189/128 mmHg; his pulse was 92 beats per minute; body temperature was $36.9{ }^{\circ} \mathrm{C}$; respiratory rate was 18 breaths per minute, and the oxygen saturation level was $98 \%$ while breathing ambient air. No swelling of the lymph nodes was palpable. His physical examination was otherwise normal. Laboratory data showed a white blood cell count of $11,100 / \mathrm{mm}^{3}$, platelet count of $73,000 / \mathrm{mm}^{3}$, international normalized ratio for prothrombin time of 1.15 , fibrinogen level of $102 \mathrm{mg} / \mathrm{dL}$, fibrin degradation products of $65.7 \mu \mathrm{g} / \mathrm{mL}$, d-dimer level of $18.1 \mu \mathrm{g} / \mathrm{mL}$, antithrombinIII activity of $61 \%, C$ reactive protein level of $3.63 \mathrm{mg} / \mathrm{dL}$, creatinine level of $1.32 \mathrm{mg} / \mathrm{dL}$, calcium level of $11.3 \mathrm{mg} /$ $\mathrm{dL}$, aspartate aminotransferase level of $164 \mathrm{U} / \mathrm{L}$, alanine aminotransferase level of $119 \mathrm{U} / \mathrm{L}$, alkaline phosphatase level of $547 \mathrm{U} / \mathrm{L}$, and lactate dehydrogenase level of 552 $\mathrm{U} / \mathrm{L}$. Other test results are shown in Table 1 . These laboratory data suggested that the patient had DIC.

Abdominal ultrasonography showed mild splenomegaly. Non-contrast chest computed tomography (CT), gastrointestinal endoscopy, and colonoscopy detected no abnormal findings. Non-contrast abdominal CT revealed multiple bone masses (Fig. 1); however, no tumors were found in the liver, adrenal glands, kidneys, bladder, prostate, or pancreas. Therefore, a bone marrow biopsy was performed at the left iliac, revealing poorly differentiated adenocarcinoma cells (Fig. 2). Immunohistochemical studies of the biopsy specimen showed positivity for keratin 7 , carcinoembryonic antigen (CEA), and cancer antigen (CA) 19-9; negativity for prostatic acid phosphatase (PAP) and napsin A, while inconclusive for keratin 20 and thyroid transcription factor (TTF)-1. Positron emission tomography (PET)-CT disclosed diffuse abnormal uptake in the bones and tail of the pancreas (Fig. 3), and contrast enhanced whole-body CT depicted a tumor of approximately $28 \mathrm{~mm}$ in diameter with poor enhancement in the pancreatic tail (Fig. 4). The patient's final diagnosis was pancreatic cancer located in the tail of the pancreas with diffuse bone metastases and DIC. His DCBM was thus believed to originate from the pancreatic cancer.

We administered nafamostat mesilate to treat DIC and opioid analgesics to relieve the patient's lumbago and sharp osteocopic pain. However, we were unable to administer systemic chemotherapy owing to his poor condition. The patient's general status rapidly deteriorate, and he was transferred to a palliative care unit (PCU). Laboratory data at discharge are shown in Table 1 . He died at the PCU approximately 2 months after admission to our hospital.

\section{Discussion}

A pathological condition derived from carcinoma and diffuse bone metastases with DIC was first reported by Jarcho in 1936 [4]. Hayashi et al. later defined such a pathological condition with DIC or microangiopathic
Table 1 Laboratory Data

\begin{tabular}{|c|c|c|}
\hline Variable & $\begin{array}{l}\text { On } \\
\text { Admission }\end{array}$ & $\begin{array}{l}\text { Two Weeks } \\
\text { after Presentaion }\end{array}$ \\
\hline White blood cell count (per $\mathrm{mm}^{3}$ ) & 11100 & 12100 \\
\hline \multicolumn{3}{|l|}{ Differential count (\%) } \\
\hline Neutrophils & 73 & \\
\hline Lymphocytes & 15 & \\
\hline Monocytes & 9 & \\
\hline Eosinophils & 0 & \\
\hline Basophils & 0 & \\
\hline Myelocytes & 3 & 5.0 \\
\hline Metamyelocyte & 0 & 1.0 \\
\hline Hemoglobin (g/dL) & 15.0 & 14.5 \\
\hline Hematocrit (\%) & 42.6 & \\
\hline Platelet count (per mm³) & 73000 & 75000 \\
\hline $\begin{array}{l}\text { international normalized ratio } \\
\text { for prothrombin time }\end{array}$ & 1.15 & 2.14 \\
\hline $\begin{array}{l}\text { Activated partial-thromboplastin } \\
\text { time (sec) }\end{array}$ & 29.8 & 41.7 \\
\hline Fibrinogen (mg/dL) & 102 & 150 \\
\hline $\begin{array}{l}\text { Fibrin degradation products } \\
(\mu \mathrm{g} / \mathrm{mL})\end{array}$ & 65.7 & 98.8 \\
\hline D-dimer $(\mu \mathrm{g} / \mathrm{mL})$ & 18.1 & 34.7 \\
\hline Antithrombin- III activity (\%) & 61 & \\
\hline$C$ reactive protein $(\mathrm{mg} / \mathrm{dL})$ & 3.63 & 8.56 \\
\hline Total protein (g/dL) & 7.1 & \\
\hline Albumin (g/dL) & 4.2 & 3.8 \\
\hline Blood urea nitrogen (mg/dL) & 27 & 36 \\
\hline Creatinine (mg/dL) & 1.32 & 1.44 \\
\hline Sodium (mEq/L) & 143 & \\
\hline Potassium (mEq/L) & 3.3 & \\
\hline Chloride (mEq/L) & 104 & \\
\hline Calcium (mg/dL) & 11.3 & \\
\hline Total bilirubin (mg/dL) & 1.2 & \\
\hline Direct bilirubin (mg/dL) & 0.5 & \\
\hline Asparate aminotransferase $(U / L)$ & 164 & \\
\hline Alanine aminotransferase $(\mathrm{U} / \mathrm{L})$ & 119 & \\
\hline Alkaline phosphatase (U/L) & 547 & 1012 \\
\hline Lactate dehydrogenase $(\mathrm{U} / \mathrm{L})$ & 552 & 608 \\
\hline Carcinoembryonic antigen $(\mathrm{ng} / \mathrm{mL})$ & 23.6 & \\
\hline Carbohydrate antigen 19-9 (U/mL) & 72836 & \\
\hline Span-1 (U/mL) & 5200 & \\
\hline DUPAN-2 (U/mL) & 440 & \\
\hline
\end{tabular}

hemolytic anemia as DCBM [1]. Almost all the previously published reports have shown that DCBM results from gastric cancer, colon cancer, lung cancer, and breast cancer [5]. To the best of our knowledge, only 
A

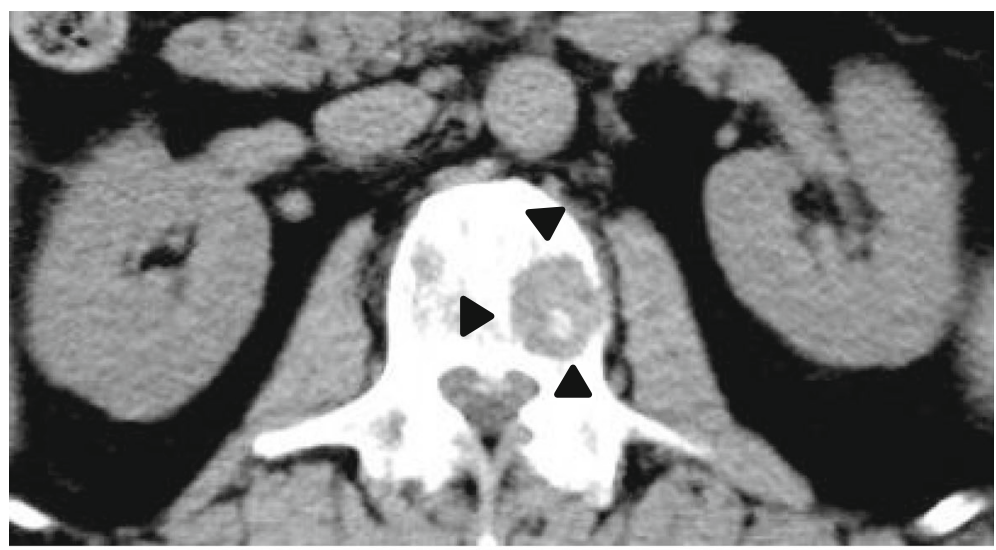

B

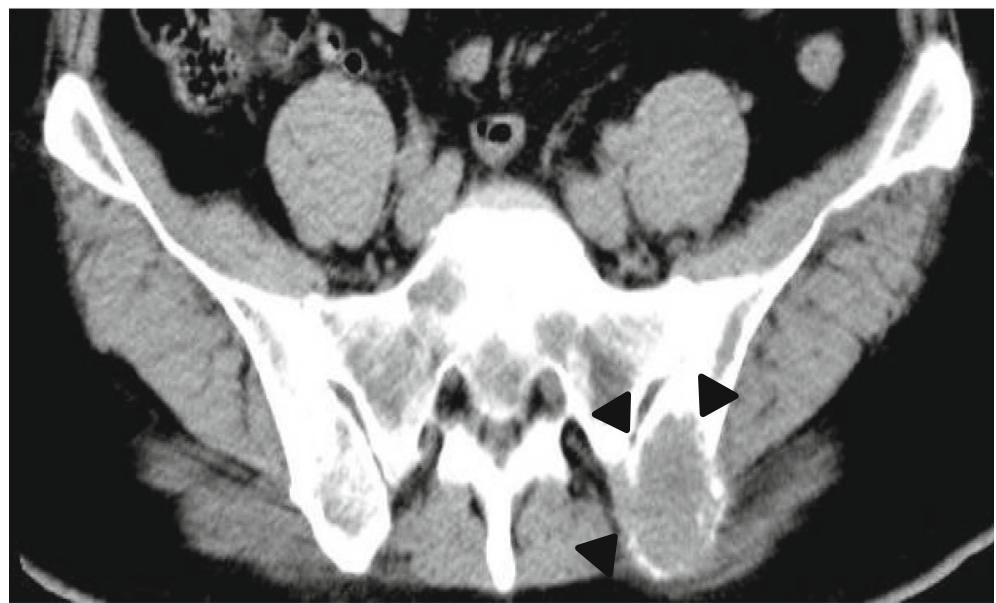

Fig. 1 Non-contrast abdominal computed tomography (CT) images. a: Multiple bone masses; b: Multiple bone masses (black arrowheads) from the abdominal area

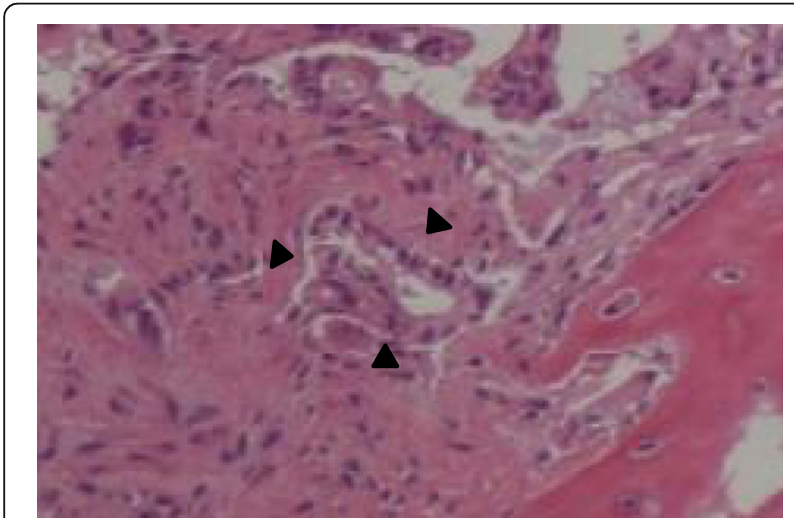

Fig. 2 Bone marrow biopsy. Hematoxylin and eosin staining of the bone marrow biopsy performed at the left iliac revealed adenocarcinoma cells $(\times 400$, black arrowheads) one prior report has described pancreatic cancer as the origin of DCBM [6]. In the present case, contrast wholebody CT revealed a tumor with poor enhancement in the tail of the pancreas and multiple bone masses. No other abnormal structures were identified by CT, gastrointestinal endoscopy, or colonoscopy, whereas PET-CT demonstrated diffuse abnormal skeletal uptake. Laboratory data in the above-mentioned case showed marked elevation of Span-1 and DUPAN-2 and DIC, while the left iliac bone marrow biopsy revealed adenocarcinoma cells. Such findings were probably indicative of pancreatic cancer with DCBM. The condition of our patient was very severe at admission, although his tumor size was significantly smaller than that in the previously reported case (28 mm vs. $55 \mathrm{~mm}$ ) [6], and he died within 2 months of diagnosis. A young age and poorly differentiated carcinoma have been suggested to be associated with poor prognosis in gastric cancer cases with DCBM 


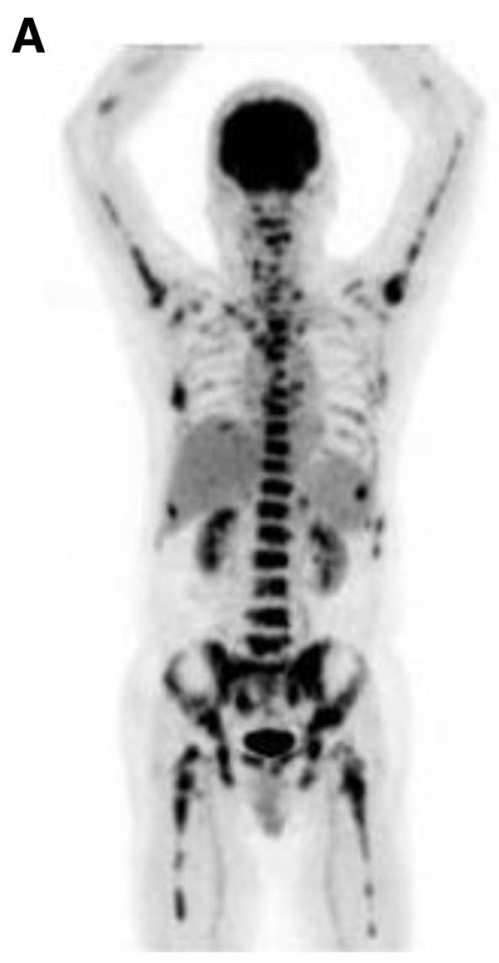

B

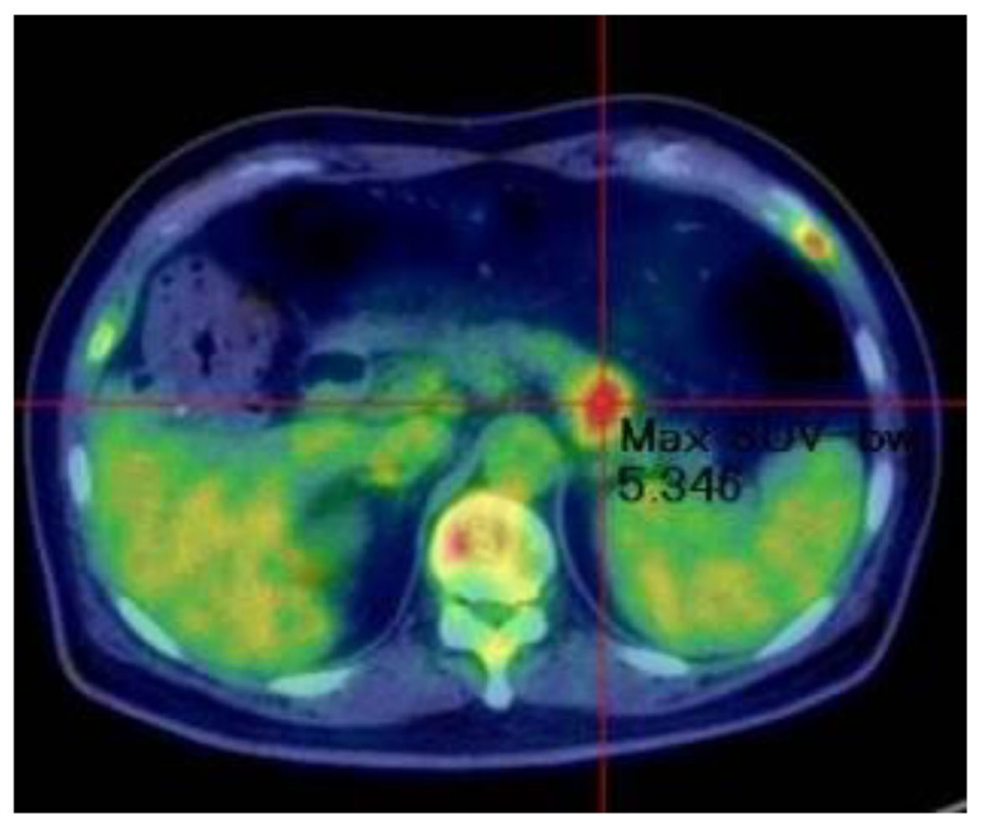

Fig. 3 PET-CT studies. a: Diffuse skeletal uptake; $\mathbf{b}$ : Abnormal uptake in the tail of the pancreas

$[1,7]$. Our patient was diagnosed at 57 years of age and had poorly differentiated carcinoma, which might explain his extremely poor prognosis despite a small pancreatic tumor size.

A previous report indicates that the tumor detection rate with non-contrast CT was $23 \%$ when tumor size was less than $20 \mathrm{~mm}, 59 \%$ for tumors measuring less than $40 \mathrm{~mm}$, and $100 \%$ in cases of tumors measuring more than $40 \mathrm{~mm}$ [8]. In the present case, the tumor size was $28 \mathrm{~mm}$, and it was undetectable via noncontrast CT. It was subsequently found by PET and contrast-enhanced CT imaging. 


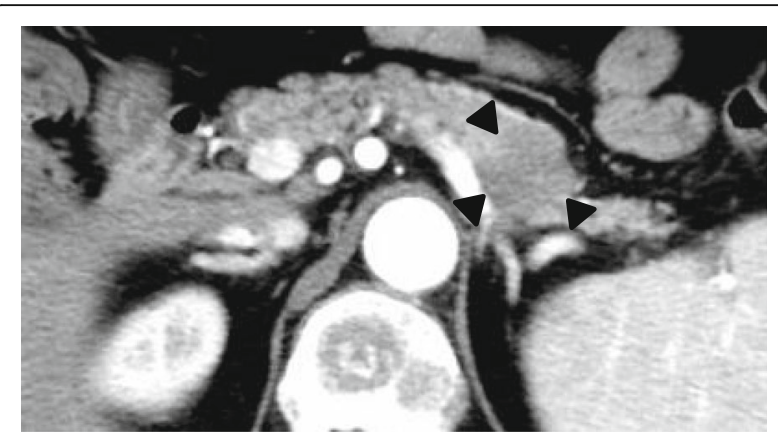

Fig. 4 Contrast-enhanced whole-body $C T$ image. A tumor of approximately $28 \mathrm{~mm}$ in diameter with poor enhancement was detected in the tail of the pancreas (black arrowheads)

While the serum CA19-9 levels were normal in cases of gastric cancer with DCBM [9-12], the serum CA19-9 levels were markedly elevated in cases of pancreatic cancer with DCBM in the present study as well as those in a previous study [6]. Although the mechanism for this finding is unknown, the extremely high CA 19-9 levels might be helpful in the early diagnosis of pancreatic cancer with DCBM before the histopathological examination results are obtained.

Exacerbation of DCBM occurs rapidly, and the mean survival time is 4.6 months after the onset of DCBM [9]. A proper diagnosis and timely administration of chemotherapy and treatment of DIC are crucial to prolong survival [13]. Pancreatic tumors are occasionally challenging to detect with non-contrast CT. Therefore, it is important to consider the pancreas as a possible origin of DCBM and perform contrast-enhanced CT when multiple bone metastases are observed.

\section{Conclusions}

We herein describe a case of pancreatic cancer located in the tail of the pancreas with diffuse bone metastases and DIC, which, in our case, was DCBM. This is the first case report to demonstrate DCBM arising from the small pancreatic cancer, to the best of our knowledge. Therefore, in cases of DCBM with an unknown primary tumor, pancreatic cancer should be considered during differential diagnosis to properly identify the primary site for the timely administration of chemotherapy and DIC treatment.

\footnotetext{
Abbreviations

CA 19-9: Carbohydrate antigen 19-9; CEA: Carcinoembryonic antigen; CT: Computed tomography; DCBM: Disseminated carcinomatosis of the bone marrow; DIC: Disseminated intravascular coagulation; PAP: Prostatic acid phosphatase; PCU: Palliative care unit; PET: Positron emission tomography; TTF-1: Thyroid transcription factor-1
}

\section{Acknowledgements}

Not applicable.

\section{Funding}

Not applicable.
Availability of data and materials

Not applicable.

\section{Authors' contributions}

$\mathrm{NH}$ was the primary treating physician for the patient and drafted and revised the manuscript. TY took care of the patient, drafted and revised the manuscript. MA, KM, KS, MM, and ST diagnosed and treated the patient, drafted and revised the manuscript. IT and TH also treated the patient, assisted in drafting the manuscript and revised it. All authors have approved the final manuscript.

\section{Competing interests}

The authors declared that they have no competing interests.

\section{Consent for publication}

Written informed consent was obtained from the patient's wife for publication of this case report and any accompanying images. A copy of the written consent is available for review by the Editor of this journal.

\section{Ethics approval and consent to participate}

Not applicable.

\section{Author details}

${ }^{1}$ Department of Medical Education and General Practice, Osaka City University, Graduate School of Medicine, 1-4-3, Asahi-machi, Abeno-ku, Osaka 545-8585, Japan. ${ }^{2}$ Department of Emergency and General Practice, Higashi Sumiyoshi Morimoto Hospital, 3-2-66, Takaai, Higashisumiyoshi-ku, Osaka 546-0014, Japan. ${ }^{3}$ Department of Palliative Care, Higashi Sumiyoshi Morimoto Hospital, 3-2-66, Takaai, Higashisumiyoshi-ku, Osaka 546-0014, Japan.

Received: 1 August 2015 Accepted: 10 October 2016

Published online: 13 October 2016

\section{References}

1. Hayashi H, Haruyama H, Emura Y, Kaizuka I, Ozeki T. Disseminated carcinomatosis of the bone marrow - Study of a type of metastatic cancer and relationship of microangiopathic hemolytic anemia or disseminated intravascular coagulation. Jpn J Cancer Clin. 1979;25(4):329.

2. Rhee J, Han SW, Oh DY, Im SA, Kim TY, Bang YJ. Clinicopathologic features and clinical outcomes of gastric cancer that initially presents with disseminated intravascular coagulation: a retrospective study. J Gastroenterol Hepatol. 2010;25(9):1537-42.

3. Ikarashi M, Wakabayashi K, Omori K, Ebisawa K, Yamada K, Itou Y. A case of early gastric cancer complicated with UL-IV gastric ulcer with super bone scan. Jpn J of Gastroenterol Surg. 2012;45(2):139.

4. Jarcho S. Diffusely infiltrative carcinoma. A hitherto undescribed correlation of several varieties of tumor metastasis. Arch Pathol. 1936;22:674.

5. Hasuda N, Koshizuka K, Oyachi N, Takano K, Matsumoto M. A case report of disseminated carcinomatosis of the bone marrow from early gastric cancer 4 years after operation. J Jpn Surg Assoc. 2008;69(2):355-9.

6. Nakamura K, Takamori H, Nakahara O, Ikuta Y, Kuroki H, Nakagawa S, Mima K, Okabe H, Nitta H, Imai K, Chikamoto A, Doi K, Ishiko T, Beppu T, Iyama K, Baba $\mathrm{H}$. A case of cancer the pancreatic tail with disseminated carcinomatosis of the bone marrow. Jpn J Canc Chemother. 2012;39(8):1275-7.

7. Yamamura Y, Kito T, Yamada E. Clinical evaluation on bone and bone marrow metastasis of gastric carcinoma. Jpn Soc of Gastroenterol Surg. 1985;18(11):2288-93.

8. Karasawa E, Saisho H. Early diagnosis of carcinoma of the pancreas with emphasis on utility of ultrasonography. Jpn J Gastroenterol. 1989;86(12):2794-803.

9. Kimura A, Kawasaki H, Wajima N, Nakai M, Nakayama Y, Yonaiyama S, Hakamada K. A case of rapidly fatal gastric cancer with disseminated carcinomatosis of the bone marrow. Jpn J Canc Chemother. 2013;40(12):2322-4.

10. Yamagishi T, Miura K, Ninomiya H, Sasaki T, Katsumi R, Matsuba A. A case of disseminated carcinomatosis of bone marrow appeared by lumbago. Tohoku J Orthop Traumatol. 2010;54(1):80-3.

11. Takeda A, Kawara F, Onishi K, Higashida A, Mamori S, Ashida C, Okutani T, Yamada $\mathrm{H}$, Kondo T. A very elderly case of advanced gastric cancer with disseminated carcinomatosis of bone marrow and multiple bone metastases, diagnosed by extremely elevated serum alkaline phosphatase levels, and treated with low-dose S-1 to avoid disseminated intravascular coagulation. Nippon Shokakibyo Gakkai Zasshi. 2011;108(11):1879-85. 
12. Takeda H, Nishikawa H, Tsumura T, Sekikawa A, Maruo T, Okabe Y, Kimura T, Wakasa T, Osaki Y. Prominent hypereosinophilia with disseminated intravascular coagulation as an unusual presentation of advanced gastric cancer. Intern Med. 2014;53(6):563-9.

13. Kikuchi Y, Matsuzaki M, Tokura N, Kanayama K, Kanayama M, Shiratori M, Shinohara M, Igarashi $Y$, Sumino $Y$, Nakano K. Disseminated carcinomatosis of the bone marrow due to gastric cancer: analysis of cases at Toho University and in Japan. J Med Soc Toho. 2010;57(2):127-36.

Submit your next manuscript to BioMed Central and we will help you at every step:

- We accept pre-submission inquiries

- Our selector tool helps you to find the most relevant journal

- We provide round the clock customer support

- Convenient online submission

- Thorough peer review

- Inclusion in PubMed and all major indexing services

- Maximum visibility for your research

Submit your manuscript at www.biomedcentral.com/submit 